\title{
MALES AND MENTAL HEALTH: A PUBLIC HEALTH APPROACH
}

\author{
Ben Nielsen, Elena Katrakis, and Beverley Raphael \\ Centre for Mental Health \\ NSW Department of Health
}

This article describes the mental health of men and boys in NSW and their utilisation of mental health services. Factors that are driving change in government policy that aim to improve mental health are explored, including the strategies of the NSW Department of Health.

\section{MENTAL HEALTH PROBLEMS AFFECTING MALES}

It is often suggested that mental disorders are more common in females than males. However, recent findings suggest that males are just as likely to suffer from mental disorders. The difference between the sexes is in the pattern of disorder. For instance, mental disorders more prevalent in males involve alcohol and other drug use and antisocial behaviour. $^{1}$

The mental health problems of boys pose a significant public health issue. Fifteen percent of boys aged 4-13 years experience mental health problems; ${ }^{2}$ boys attend mental health services more frequently than girls; and boys are more frequently involved in criminal activity and are remanded in custody than girls. A range of severe mental disorders, such as Attention Deficit Hyperactivity Disorder and Conduct Disorder, are experienced by boys at higher levels than girls.

Schizophrenia is a serious mental illness that affects one in a hundred Australians. While males and females may be equally at risk of developing schizophrenic disorders, males have an earlier age of onset and a poorer outcome than females. ${ }^{3}$ This suggests that males may often have a more severe form of the disorder with a poorer response to treatment.

Clinical depression is an illness such as major depression and dysthymia (that is, neurosis and introversion, anxiety, compulsive behaviour, and relatively mild depression). Clinical depression is a medical condition that affects the way someone feels, causing a persistent lowering of mood. Depression can lead to serious short- and long-term problems, including severe psychological distress, feelings of hopelessness, social withdrawal, a breakdown in family and personal relationships, and poor academic and work performance. ${ }^{4}$

Depression is a leading cause of illness and disability, both in Australia and internationally. Overall, 5.8 per cent of the Australian population has one or more depressive disorders, which are more frequent in females ( 7.4 per cent) than in males (4.2 per cent). ${ }^{5}$ Globally, depression was the fourth leading cause of disease-burden in 1990, and according to the World Health Organization, by 2020 depression will be among the three leading causes of disease-burden. ${ }^{6}$ Females will bear a particularly heavy share of this disorder, but males are frequently not diagnosed - especially young males.

Males are more likely to have a substance-use disorder than females, ${ }^{6}$ which accounts for 31 per cent of male mental health 'disability-adjusted life years' (lost years of healthy life). ${ }^{7}$ Substance use frequently involves alcohol and other psychoactive drugs such as cannabis, heroin, and cocaine. While males and females have similar prevalence of coexisting mental health and substanceuse disorders, males are more likely to have substance-use disorders in combination with either anxiety (13 per cent) or affective disorders ( 8.4 per cent) ${ }^{8}$

There is statistical data available describing the mental health problems of Aboriginal males. Many of the mental health problems identified in Aboriginal males are linked to historical factors such as disruption at colonisation, institutionalisation, and separation from natural family.

The mental health problems of Aboriginal males include misuse of alcohol, violence, destructive behaviours, and the loss of a sense of personal worth. ${ }^{9}$ Aboriginal males generally start drinking earlier, consume alcohol at more hazardous levels and more frequently than Aboriginal females. ${ }^{10}$ Indigenous people also have higher levels of psychosocial distress compared with non-indigenous people. This difference is most apparent among young people than older people. ${ }^{11}$

Mental health problems among Aboriginal males may be related to a historical fear of hospitals, 'lack of closure' and unresolved conflict due to past government policy and practice, and the past separation of mothers and children. Additional factors include the reduction of authority and status within families, sociological changes to the male role model in society generally, and the intervention of family courts and government departments.

Mental disorders for men aged 65 years and over include dementia, depression, substance-use disorder, anxiety, and affective disorders. Some older men may have been living with mental health problems for most of their lives, which means they enter their old age with a history of chronic illness and distress. ${ }^{12}$ Research also shows a strong correlation between depression, isolation, and povertyand depression is implicated in a number of suicides in this age group.

\section{SUICIDE IN MALES}

Males in NSW have higher suicide rates than females across all age groups. The death rate from suicide for 1996-97 was almost four-fold for males (20.9 deaths per 100,000) compared to females (5.4 deaths per 100,000). This probably reflects the fact that males use more lethal means when attempting suicide. ${ }^{13}$

In Australia, the overall increase in suicide rates in males of all ages is due to an increase in the rate of suicide in the 
20-39 year age group. The overall rate of suicide has declined in men between $45-75$ years of age ${ }^{15,20}$ however, it is unclear whether this decline continues or has plateaued. ${ }^{14}$ Suicide rates for males living in rural areas are also higher than those for males living in urban areas. $^{20,15}$

Compared to Australian born males, male migrants from Northern and Eastern Europe have a significantly higher risk of suicide; and male migrants from Southern Europe, the Middle East, and Asia have a significantly lower risk of suicide. ${ }^{16}$

The average suicide rate for men who have never married is more than twice as high as those who are married, and the rates for widowers and divorced men is about three times higher. ${ }^{17}$

Suicide of indigenous people is concentrated in the younger age groups for both males and females. The suicide risk for Aboriginal males aged 15-19 years has been identified as four times that of the general population. $^{13}$

\section{HEALTH SERVICES UTILISATION BY MALES}

There is a paucity of reliable data sources on the use of mental health services by males in NSW. The National Minimum Data Set-Institutional Mental Health Services provides basic information on the use of inpatient health services by mentally-disordered males in all age groups. ${ }^{5}$ The NSW Department of Health is currently implementing the 'Community Mental Health Care National Minimum Data Set', 5 which will provide information about male use of community mental health services.

Results from the National Health Survey indicate that utilisation of health services by males is lower than that of females in all areas of health care except injury. ${ }^{5}$ Young males, Aboriginal males, rural males, and males from marginalised groups demonstrate lower levels of health service utilisation. ${ }^{18}$

Further results from the National Survey of Mental Health and Wellbeing on the patterns of service use by people with a diagnosable mental disorder showed that 70 per cent of males did not access services, including psychiatrists, psychologists, other mental health professionals or other health professionals. ${ }^{5}$ The higher prevalence of risk factors and lower utilisation of health services inevitably results in higher morbidity and disability.

Carers of people with mental health problems face a range of pressures and responsibilities in their caring roles. While the majority of people reporting themselves as carers are females, studies have shown that male carers are less active in initiating contact with services than female carers. ${ }^{19}$

It is clear that males tend to delay seeking health assistance longer than females. Poor access to prevention and early intervention services is a problem for many males. With more males than females engaged in full-time employment, accessing mental health services during work hours may also be difficult. Those employed in farming or shift work industries, particularly rural areas, face geographical as well as time restraint issues in accessing services.

Males are generally more reluctant to seek help as this may be seen as a threat to their masculinity (stigma), and often they will turn to alcohol instead. Further, mental health interventions may be provided in settings that create barriers against males, or males may not feel comfortable in attending the service. For instance, health promotion activities may be held at community health centres or baby health clinics, places where many males may not feel comfortable accessing services.

\section{GOVERNMENT POLICY RESPONSES: MEN AND MENTAL HEALTH}

Both the NSW and Commonwealth Governments have begun to examine ways to address male mental health issues. The NSW Department of Health's Moving Forward in Men's Health includes strategies for male mental health needs, including suicide prevention. The NSW Department of Health's Aboriginal Men's Health Implementation Plan has been completed and includes mental health issues as a focus area.

NSW participation in initiatives of the National Mental Health Strategy relevant to men's health include the National Action Plan for Promotion, Prevention and Early Intervention for Mental Health, which identifies the need to address mental health care utilisation by young males; ${ }^{20}$ The National Action Plan for Suicide Prevention provides policy directions for suicide prevention programs at a national level, and has identified males as a target group for planning, implementation and evaluation of activities. $^{21}$

New public health initiatives are currently being identified and implemented collaboratively between the NSW Department of Health's Centre for Mental Health, the Commonwealth Department of Health and Aged Care, and the National Suicide Prevention Board, specifically including strategies for 25-44 year old males at risk of suicide.

\section{THE RESPONSE OF NSW AREA HEALTH SERVICES}

Area Health Services across NSW have implemented a number of initiatives to make mental health services more accessible to men.

During 2000 and 2001, men's health seminars have been undertaken by the New England Area Health Service. These have been provided by community health staff and delivered in the local pub at 4-6 weekly intervals. Different topics which are applicable to male mental health have been addressed, including depression, stress management and positive mental health. 
The Transcultural Mental Health Centre has established a Men's Mental Health Forum, and works in partnerships with the Men's Health Information and Resource Centre at the University of Western Sydney and other services. These partnerships focus on the mental health needs of males from culturally and linguistically diverse communities.

'Men and Depression' is a project funded by South Western Sydney Area Health Service and sponsored by numerous partners, such as community health services, Fairfield Health Service, Fairfield City Council, nongovernment organisations, and local area health service staff. This project has developed resources for men, both younger and older, with a focus on depression.

The majority of older people who are homeless or live in poverty or squalor are men. This may be the result of mental illness, alcohol abuse, or a combination of social circumstances. Community mental health services and non-government organisations across NSW provide outreach services to these groups.

\section{CONCLUSION}

It is frequently suggested that mental disorders are more common in females than in males. However, recent population surveys suggest that, while females and males may differ in the type of mental disorder that they manifest, the proportion experiencing a mental disorder is remarkably similar.

The identification and explanation of gender differences in mental disorder is increasingly translated into policy development and new directions for service delivery throughout NSW Health. This includes the need to ensure equitable access to mental health services, which are planned and delivered to meet gender specific needs.

The Centre for Mental Health at the NSW Department of Health is committed to planning, policy development and service delivery that is sensitive to the different patterns of health behaviour determined by gender. A forum to address men and mental health is planned for 2002, which will bring together policy makers, service providers, consumers and carers and individuals, and offers opportunities for networking and the sharing of experiences.

\section{ACKNOWLEDGEMENTS}

The authors wish to acknowledge the valuable contributions to this article by Dr Stan Catts, Warren Bartik, Ms Guncha Ansari, and Dr Leonie Cox.

\section{REFERENCES}

1. Policy Division. Moving Forward in Men's Health. Sydney: NSW Department of Health, 1999.

2. Sawyer MG et al. Child and Adolescent Component of the National Survey of Mental Health and Well-being. Canberra: Commonwealth Department of Health and Aged Care, 2000.
3. Bardenstein KK and McGlashan TH. Gender Differences in Affective, Schizoaffective and Schizophrenic Disorders. A Review. Schizophrenia Research 1990 (3): 159-172.

4. National Health and Medical Research Council. Clinical Practice Guidelines: Depression in Young People. Canberra: NHMRC, 1997.

5. Andrews G et al. National Survey of Mental Health and Wellbeing-Report 2: The Mental Health of Australians. Canberra: Commonwealth Department of Health and Family Services, 1999.

6. Murray CJL and Lopez AD (editors). The Global Burden of Disease. Harvard, Mass: Harvard School of Public Health for the World Health Organization, 1996.

7. Australian Institute of Health and Welfare. Institutional Mental Health Services in Australia 1997-98. Canberra: AIHW, 2000.

8. NSW Department of Health. The Management of People with a Co-existing Mental Health and Substance Use Disorder. Sydney: NSW Department of Health, 2000.

9. Swan P and Raphael B. Ways Forward: National Consultancy Report on Aboriginal and Torres Strait Islander Mental Health. Canberra: Commonwealth of Australia, 1995.

10. Australian Bureau of Statistics. The Health and Welfare of Australia's Aboriginal and Torres Strait Islander People Supplement. Canberra: Australian Bureau of Statistics, 1997.

11. Public Health Division. The Health of the People of NSWReport of the Chief Health Officer 2000. Sydney: NSW Department of Health, 2000.

12. NSW Department of Health. Caring for Older People's Mental Health. Sydney: NSW Department of Health, 1999.

13. NSW Department of Health. Suicide in NSW: We Need to Know More (The NSW Suicide Data Report). Sydney: NSW Department of Health, 2000.

14. Cantor C, Neulinger K and Leo D. Med J Aust 1999; 171:137141.

15. Australian Bureau of Statistics. Suicide Australia: 1921-1998. Canberra: Australian Bureau of Statistics, 2000. Catalogue no: 3309.0 .

16. Morrell S, Taylor R, Slaytor E, Ford P. Urban and rural suicide differentials in migrants and the Australian-born, New South Wales, Australia 1985-1994. Social Science \& Medicine 1999; 49: 81-91.

17. Australian Bureau of Statistics. Australian Social Trends 2000: Health-Mortality and Morbidity (Suicide Rates 1995-97). Canberra: Commonwealth of Australia, 2000

18. House of Representatives Standing Committee on Family and Community Affairs. Men's Health: Summary Report of a Seminar. Canberra: Parliament of the Commonwealth of Australia, 1997.

19. Australian Bureau of Statistics. Disability, Ageing and Carers: Summary of Findings. Canberra: Australian Bureau of Statistics, 1998. Catalogue number 4430.0.

20. Commonwealth Department of Health and Aged Care. National Action Plan for Promotion, Prevention and Early Intervention for Mental Health. Canberra: Commonwealth Department of Health and Aged Care, 2000.

21. Commonwealth Department of Health and Aged Care. National Action Plan for Suicide Prevention-Consultation Draft, December 1998. Canberra: Commonwealth Department of Health and Aged Care, 1998. 